action, in which he quoted the experimental results of an investigation of the action of invertase on cane sugar ; these results confirm the conclusion of previous workers that the action of inversion does not follow the simple law of mass action, but the author does not regard the action as independent of mass in. fluence. He considers that the influence of mass in inversion changes is restricted by some other and hitherto unrecognised influence, and this he believes he has found in the time factor of molecular change. In reply to remarks by Prof. Reynolds Green, the author stated that his results were not necessarily in disaccord with those of Croft Hill. A paper was read by Prof E. A. Letts and Mr. R. F. Blake, on the chemical and biological changes occurring during the treatment of sewage by the so-called bacteria beds. A large portion of the unoxidised nitrogen present in sewage disappears during the passage of the sewage through the so-called bacteria beds, and the authors consider that this may be due either to escape of the nitrogen in the gaseous state as free nitrogen or possibly as oxides or to the passage of the nitrogen into the tissues of animals or vegetables; both of these causes of loss may operate at the same time. An examination of sewage matter before and after passage through the beds showed that in nearly all cases the amount of dissolved nitrogen present in the sewage was greater after treatment than before, although, of course, if free nitrogen were evolved, only a minute fraction of it would remain dissolved in the sewage effluent. With respect to the possible biological explanation of the loss, it is pointed out that the sewage beds at Belfast and other places swarm with minute insects (Podura aquatica), and that species of worms are also present; these in feeding on the sewage undoubtedly cause a loss of nitrogen. A paper was then read by Dr. S. Rideal on humus and the so-called irreducible residue in bacterial treatment of sewage, in which the results were detailed of a number of analyses of the humus-like substance or so. called irreducible residue produced in bacterial sewage beds. It is shown that in this material the ratio of carbon to nitrogen and the percentage of nitrogen in the organic matter present are very nearly the same as in humus mould; the conclusion is drawn that if sewage has undergone proper bacterial fermentation the small quantity of peaty deposit formed is of the nature of humus and is practically inoffensive. In a paper on sulphuric acid as a typhoid disinfectant, Dr. S. Rideal advocated the use of sulphuric acid, either as such or in a more portable form as sodium bisulphate, for destroying the Bacillus typhosus in potable waters or in drainage from isolation hospitals. Mr. W. Ackroyd gave a paper on the inverse ratio of chlorine to rainfall, in which it was shown that when the observation periods are shortened to daily estimations of the chlorine, minimal amounts of rainfall are marked by maximum contents of chlorine, and vice versî. In a second paper, Mr. Ackroyd dealt with the distribution of chlorine in Yorkshire. Mr. G. T. Beilby, in a paper on the minute structure of metals, showed that the microscopic examination of metallic surfaces has revealed that metals occur in two forms, viz., as minute scales or "spicules" $(a)$ and as a transparent glass-like substance (b). The spicules do not vary much in size in the different metals and have a diameter of $1 / 300$ to $1 / 400$ of a millimetre; the form $a$ passes into the form $b$ when the metal is pressed or hammered, and all polished metallic surfaces are covered with a thin layer of this transparent form as with a lacquer or enamel. Prof. G. G. Henderson and Mr. G. T. Beilby read a paper on the action of ammonia on metals at high temperatures ; on exposing platinum, copper, gold, silver, iron, nickel and cobalt to ammonia gas at $600^{\circ}$ to $900^{\circ}$ disintegration of the metal occurs, whilst a large proportion of the ammonia is decomposed into its elements. After the treatment the metal shows a spongy or cellular structure, as if it had been rapidly cooled whilst in a state of effervescence; copper and iron rods of a quarter of an inch diameter are penetrated to the centre by the ammonia gas within half an hour, and copper exposed to the action of ammonia gas for seven days at $800^{\circ}$ falls to a fine powder. Dr. W. C. Anderson and Mr. G. Lean gave a paper on aluminium-tin alloys, in which they show that these alloys evolve hydrogen freely when placed in water; the microscopic examination of the water-corroded plates of alloy indicates that contact action between the excess of tin and the aluminium-tin compound is responsible for the spontaneous oxidation. Prof. Willy Marckwald, of Berlin, gave a very interesting demonstration and description of the properties of radium; he had surmised, from the work of $\mathrm{P}$. and $\mathrm{S}$. Curie, that the barium salt extracted from pitchblende contains the radium salt as an isomorphous constituent, and that the process used by these workers for separating a strongly radio-active salt from the barium compound is probably similar to that in use for isolating the constituents of an isomorphous mixture. He therefore fractionally crystallised the barium chloride prepared from pitchblende from water, and found that pure barium chloride first separates and then a material, probably the eutectic mixture, which is very rich in the radio-active component. The most strongly radio-active fractions have the power of immediately discharging a charged gold leaf electroscope when at the distance of half a metre from the latter and when preserved under colourless glass soon turn it a deep brown colour. The radio-active substance is strongly luminescent in a dark room, and on interposing the hand between the preparation and a barium platino-cyanide screen, the bones in the fingers are seen sharply delineated on the screen. Prof. Marckwald also exhibited several preparations of so-called "phototropic" substances, compounds which change colour on exposure to sunlight and recover their original tint on preservation in a dark place; he mentioned that the rapidity of change in either direction is considerably influenced by the temperature. Prof. A. Michael, of Boston, read papers on the genesis of matter and on the process of substitution; he also contributed a paper on the three stereoisomeric cinnamic acids, in which he claimed to have proved that these three isomerides actually exist, that is, that one more isomeride exists than can be accounted for by the van 't Hoff hypothesis as in terpreted by Wislicenus. Prof. G. G. Henderson and Mr. Corstorphine read a paper on the condensation of benzil with dibenzylketone ; in this condensation a tetraphenylcyclopentenolone is produced, and on heating it with red phosphorus and hydriodic acid a mixture of tetraphenylcyclopentene and tetraphenylcyclopentane is formed. Dr. Hodgkinson and Mr. L. Limpach contributed a paper on some relations between physical constants and constitution in benzenoid amines, and Dr. G. Young gave a paper on the existence of certain semicarbazides in more than one modification. Prof. W. H. Perkin, jun., gave a brief outline of his work on the synthetical formation of bridged rings. Prof. Joji Sakurai, of Tokio, in a paper on some points in chemical education, observed that in spite of the rapid progress made in chemistry during the past fifteen years, chemical education seemed still to be carried out in an inefficient and unsatisfactory manner. $\mathrm{He}$ pleaded for the more extensive use of physical chemistry as an educational agent, but wished to replace the ordinary name of this branch of the subject by the more rational one of general chemistry. Mr. W. Thomson contributed a paper on the detection and estimation of arsenic in beer and articles of food ; after noting that arsenic is introduced into barley during the process of malting owing to the employment of anthracite coal or coke containing arsenic, he suggested that all beers in 50 c.c. of which arsenic could be detected by any test whatever should be condemned. In a report entitled "The Equilibrium Law as Applied to Salt Separation and to the Formation of Oceanic Salt Deposits," Dr. E. F. Armstrong gave an excellent résumé of the work of van 't Hoff and his pupils on the investigation of the conditions attending the formation of the German deposits of magnesium salts; the report was illustrated by the aid of a number of models. Dr. J. Gibson, in a paper on the electrolytic conductivity of halogen acid solutions, detailed the results of experiments which showed that halogen acid solutions of concentrations corresponding to a change of curvature of the electrolytic conductivity curve have altogether peculiar properties. Other papers were read by Mr. P. J. Hartog, on the flame coloration and spectrum of the nickel compounds, by Dr. Farmer, on the methods of determining the hydrolytic dissociation of salts, and by Dr. T. S. Patterson, on the influence of solvents on the rotation of optically active compounds.

\section{ENGINEERING AT THE BRITISH ASSOCIATION.}

SECTION G suffered badly at Glasgow, both in attendance and in the quality of the papers presented to it, from the Engineering Congress which was held in the University buildings during the preceding week; many regular members of the Section were absent, and several valuable papers which would under ordinary circumstances have come to the Section were read instead at one or other of the Congress sectional meetings. On the opening day, after the presidential address, 
since the engineering departments of the Glasgow International Exhibition would naturally be frequently visited by members of the Section, it was arranged to have a paper descriptive of the mechanical exhibits; this was given by Mr. D. H. Morton, and proved most useful in assisting visitors to spend to the best advantage the hours they gave up to the Exhibition. The author, rightly enough, deplored the almost complete absence of any marine engineering exhibits and the poor show of locomotives; but he pointed out that in another of the great industries of Glasgow, steel making, there was a remarkably complete and most instructive series of exhibits, the enormous steel plates and huge steel forgings and castings being especially interesting. On the same day two interesting papers by Mr. J. R. Wigham, on a long-continuous-burning petroleum lamp for beacons and buoys, and on a new scintillating lighthouse light, were also read. In the first paper the author claimed that by burning petroleum and using the wick horizontally, so that the flame sprang from the side and not from the edge or ends, a steady light could be secured requiring no attention for a month; the slow continuous movement of the wick over the roller was secured by an ingenious arrangement in which the gradual escape of oil from a cylinder caused a float attached to the wick end to slowly descend, thus causing the wick to travel over the roller and so present a new surface to the fiame. Examples of both these appliances were on show in the University buildings.

Another paper on this day was a short note by Mr. J. E. Petavel, in which he described a recording manometer he had devised, for obtaining a record of the high pressures reached by exploding charges of gas in closed cylinders. The instrumen seemed well adapted for its purpose and ought to prove useful in gas and petroleum engine work.

Two reports were presented to the Section, one by the Small Screw Gauge Committee, in which the extreme trouble they had met with in obtaining accurate gauges was again described, and as a result practically little progress had been made since the last report was presented at Bradford; the other by the Committee on Resistance of Road Vehicles to Traction. This committee, which was appointed at Bradford, has discovered that the task it has embarked upon is a most difficult one, and one which will involve an expenditure far beyond any grants which could be given by the Association. The committee therefore sought and obtained authority to approach other bodies for financial help-many promises of substantial assistance had been given before the meeting. The work done up to date is briefly as follows: $-(a)$ a dynamometer has been designed and is in course of construction; $(b)$ a motor (lent by a member of the committee) is being fitted up to carry the dynamometer and is having a new and more powerful engine fitted to it ; $(c)$ it has been decided after careful consideration to begin the experiments by testing single wheels with various types of tyres, on artificial tracks, and then later on, with the experience gained in these preliminary investigations, the work on actual vehicles on ordinary roads will probably be much simplified. As some misapprehension exists as to the work the committee are attempting to carry out, it may be as well to state that it is work of the utmost value to the country, and work of a highly scientific character. No recent experiments have been carried out on this most important question, and designers of motor vehicles are obliged either to adopt rule of thumb methods or to fall back on data obtained by experiments made many years ago, on roads of quite different construction to those now in use, and with only one type of tyre, the solid steel or iron one. Should the committee succeed in the elaborate series of experiments they have planned, not only will designers of selfpropelled vehicles have constants and data available for their use, upon which they can place absolute reliance, but road engineers will have exact information on two questions of the greatest interest to them, the effect of the method of moving a vehicle (that is, whether hauled of self-propelled) upon the life of a road, and secondly, the relative advantages of the different materials now in use for road making in regard to the frictional resistances encountered by the vehicles moving over them.

As the president of the Section devoted a part of his address to the modern development of passenger and goods traffic, it was natural that many of the papers read before the Section should deal directly or indirectly with this subject. Mr. N. D. Macdonald, in a paper on railway rolling stock present and future, attacked in vigorous fashion railway management in this country; he undoubtedly put his finger on many weak spots, notably as regards brakes and our old-fashioned goods trucks, but, like most amateurs when dealing with professional subjects, he spoilt much of his case by exaggeration. Professional engineers, like every other class of men, are liable to errors. They are prone to prefer old-fashioned methods and are too little inclined to take up and try novelties, but, after atl, they are men of understanding and business men, and they are not likely to shut their eyes to improvements going on in other countries or to refuse to adopt them simply because foreigners first tried them. No one who travels much can fail to note the great improvements in railway management in this country during the past ten years, or the many changes still to be made if we are to keep abreast of the latest advances; but, after all, it is wiser to adopt radical changes cautiously, and we fancy the public will continue to place more reliance on the judgment of the trained expert than of the over-eager amateur.

Mr. Bunau-Varilla, formerly engineer-in-chief of the Panama Canal, in a paper on the canal, vigorously defended the judgment of those who selected that site for the canal instead of the Nicaragua route. The author gave many strong reasons for his preference for Panama; in particular he contrasted the almost entire freedom of the Panama site from seismic disturbances with the constant and ever-present danger to all concrete and masonry work all along the Nicaragua route from such causes. The case for Panama was so strongly put that it was unfortunate there was no real discussion on the paper, and therefore the arguments in favour of Nicaragua were not given a chance.

In electrical engineering, only two papers of much interest were presented, a valuable one by Prof. E. Wilson, on the commercial importance of aluminium, and a paper by $\mathrm{Mr}$. Killingworth Hedges, on the protection of buildings from lightning. Prof. Wilson, after a brief description of the latest methods of manufacture, devoted himself mainly to an account of the use of aluminium as a conductor of electricity and its advantages for this purpose. In the discussion, the president (Colonel Crompton) referred to the great difficulty in securing uniform quality in aluminium tubes and sheets, and suggested that this stumbling-biock must be removed if the extended uses of the metal which engineers hoped for were to become possible. Mr. K. Hedges drew attention to the work of the committee of British architects which was now engaged in con. sidering the question of the protection of buildings from lightning effects, and to the urgent need of the adoption of some uniform system. He described in detail his re-arrangement of the system in use at St. Paul's Cathedral in London, where the conductors put up in 1872 were found to be quite useless for the purpose they were intended to serve. He had increased the number of ordinary conductors from air to earth, and, in addition, ran horizontal cables on the ridges of the roofs and in other prominent positions, thus encircling the building. These were connected to the vertical conductors wherever they crossed, and were also furnished at intervals with aigrettes or spikes, invisible from the ground level, thus giving many points of discharge. The author drew attention to the unsuitability of soldered joints for conductors, and described his own special joint box; he also explained the tubular earth he designed to get over the difficulties brought about by the old foundations of the cathedral interfering with the use of an ordinary earth plate. In the more purely mechanical side of its work, the Section dealt with two papers of much interest. Prof. George Forbes described his "folding rangefinder for infantry," and Mr. M. Barr the machines he had designed for the manufacture of type. Prof. Forbes' instrument is of the class known as "one-man portable-base range-finders," and possesses great accuracy up to a range of 3000 yards. It was founded on Adie's original instrument. It consists of a folding aluminium base of square tube, hinged at the centre, and a field glass. At each end of the base when opened out is a doubly reflecting prism, the rays of light from any object are refiected at each of these end prisms along each half tube, and then again at the centre into the two telescopes of the binocular glass, the final directions of the rays being parallel to the original. The angle between these rays is measured by means of two vertical wires, one in each telescope, one wire is fixed, and the other can be moved by a micrometer screw until the two appear to coincide and the object appears distinctly; the distance of the object is then at once given, to within 2 per cent. in 3000 yards. The author claimed gre tt accuracy in stereoscopic vision, but Profs. Barr and Stroud, who took part in the discussion, and drew attention to the

No. I668, vOL. 64] 
somewhat different lines on which they had worked in their range-finder (of which 400 are now in use in our Navy), differed on this point from him and preferred the method of single coincidence. Mr. Barr's paper, illustrated by lantern slides, was of too highly a technical nature to be dealt with in detail in the space at our disposal, suffice it to say it bids fair to revolutionise the method of carving or engraving the natrices used in type casting. The new process dispenses with wax and electro-plating processes, and secures a pattern cut out of solid brass in a much shorter time than was possible in any of the older methods. The author described the great difficulties he had met with in this work, both in the design of a strong, rigid and easily worked pantograph and in the attempt to carve out rapidly the large amount of superfluous material in the brass plate which had to be removed in order that the design should be left clearly in relief on a smooth plane; all these had now been overcome. Special machinery had been designed capable of extraordinary accuracy for cutting rapidly the punches needed, and for grinding the cutters.

The last paper we need refer to was one by Mr. C. R. Garrard on some recent developments in chain driving, which elicited a very interesting discussion, one of the best during the meeting. $\mathrm{He}$ gave figures as to the extraordinary pressure per square inch used in chain bearings as compared with those adopted in ordinary engineering work; in an ordinary bicycle chain as high a figure as $I I, 765$ pounds per square inch may be occasionally reached; an account was given of the most recent methods of making these chains and of the quality of steel used, and, lastly, of the use of chains for high-speed driving purposes.

Apparently for the reason given before, local engineers took but little interest or share in the proceedings of the Section, and on the whole it was a disappointing meeting, both from the point of view of attendance and discussion on the papers and also in the quality and general value of the papers dealt with. Section G still calls in vain for papers from the numerous engineering laboratories throughout the kingdom; there are scores of young engineers, engaged in scientific research work, and until they can be got hold of, and the class of papers radically altered, Section $G$ will fail to appeal to the great body of engineers in the country.

T. H, B.

\section{ANTHROPOLOGY AT THE BRITISH ASSOCIATION}

- HE Anthropological Section of the British Association met in the new Anatomy Department of the Glasgow University, which was formally opened by Lord Lister on the first afternoon of the meeting. The address of the president of the Section, Prof. D. J. Cunningham, F.R.S., dealt with the human brain, and the part which it has played in the evolution of man, and is to be found in full in NATURE of Sep. tember $26, p .539$. The rest of the programme was planned as follows: Thursday morning and Monday afternoon were devoted to physical anthropology, which was represented by an unusual number of highly specialist papers; Tuesday to ethnography, chiefly American and Malayan; Friday and Monday morning to archæology ; and Wednesday to anthropometry and folklore. The principal papers are classified kelow in order of their subject-matter.

\section{Anthropography.}

Prof. J. Cleland, F.R.S., gave a demonstration of the cartilage of the external ear in the monotremata in relation to the human ear, illustrated from Echidna and Ornithorhynchus.

Dr. J. F. Gemmill illustrated, by a series of fine microscopeprojections, the origin of the cartilage of the stapes and its continuity with the hyoid arch, showing that the slapes is developed independently of the periotic capsule, and belongs to the hyoid bar.

Prof. A. Macalister, F.R.S., contributed notes on the morphology of transverse vertebral processes, with the object of determining embryologically the morphological relations of the several parts of the neural arch. A further note on the third occipital condyle showed that two distinct structures are comprised under this name-a mesial ossification in the sheath of the notochord, and a lateral and usually paired process caused by the deficiency of the mesial part of the hypochordal element of the hindmost occipital vertebra, with thickening of the lateral portion of the arch.

Principal Mackay tead a paper on supras:ernal bones in the no I 668, voL. 64] human subject, which gave rise to an animated discussion of the embryological evidence.

Prof. J. Symington combated Hochstetter's view that the "temporary fissures" of the human cerebral hemispheres are merely the product of incipient maceration and putrefaction in laboratory specimens. He admitted, however, that the arcuate fissure is of no morphological significance, and that it has nothing to do with the hippocampal fissure, which latter can be traced in the fotal brain in the position which it occupies throughout life in the monotremata and marsupialia. The rudimentary grey and white matter on the back of the adult human corpus callosum is prohably the remains of a hippocampal formation.

Mr. J. F. Tocher and Mr. J. Gray discussed the frequency and pigmentation value of the surnames of Scottish school-children in East Aberdeenshire. There is a presumption that the present possessors of surnames inherit some of the physical characteristics of their ancestors of the thirteenth and fourteenth centuries, when hereditary surnames first became common in Scotland, and this is confirmed by the fact that among $75 \mathrm{I}$ surnames noted, 63 Highland names covered 13 to $\mathrm{I} 4 \mathrm{per}$ cent. of the population; the same proportion of Highland blood as had been previously ascertained by measurements. There is wide variability in the pigmentation value of different surnames; Frasers, for example (from blonde Inverness-shire), tending to be blonde; and Robertsons and Gordons (from Perthshire and West Aberdeenshire) to be dark. A committee of the Associa. tion was appointed to assist Messrs. Gray and Tocher in organising a similar pigmentation-survey for the school-children of the rest of Scotland.

Miss Nina Layard exhibited a skull found in peat in the bed of the river Orwell, now in the museum of the College of Surgeons. It proved to be of the same pre-Roman British type which is common in the Fen district.

Mr. W. M. Douglas, superintendent of police, described the working of the Bertillon niethod of personal identification, as practised in Glasgow. In discussion, Dr. Garson laid stress on the value of the form of nose and ear in identification, as against the colour of hair and eye; pronouncing photographs useless, but finger prints most important.

\section{Ethnography.}

The Report of the Ethnographic Survey of Canada summarised the work of the year, and introduced a copious memorandum by Mr. C. Hill Tout on the natives of British Columbia. The committee was reappointed with a grant of $\mathrm{I}_{5} l$. Mr. J. O. Brant Sero, a Canadian Mohawk, gave an account of the traditional history of the Caniengahakas and their culture-hero Dekanawideh, with notes on their social and political organisation. This striking communication is printed in full in Man for November.

Mr. Hesketh Prichard described in detail the manners and customs of the Tehuelche Indians of Patagonia, and $\mathrm{Mr}$. Seymour Hawtrey those of the Lengua Indians of the Gran Chaco.

The Report of the Skeat Expedition to the Malay Peninsula contained an elaborate account of Malay industries, and was illustrated by photographs and reproductions of native im. plements and fabrics. Mr. Skeat contributed a detailed study of the Sakais and Samangs, wild tribes in the interior of the Peninsula who retain many marks of a primitive stage of culture.

Messrs. Annandale and Robinson, who are still in the field, sent a full account of the half-Siamese half-Malay community of Sai-Kau in the northerly border-state of Nawnchik, in which the two peoples live side by side and have given rise to a mixed type of culture. Physical measurements show the survival in both of a marked Negrito element.

Mr. R. Shelford propounded a provisional classification of the swords of the tribes of Sarawak.

Dr. W. H. R. Rivers discussed the functions of the maternaluncle, son-in-law and brother-in-law in Torres Straits, with the view of illustrating the underlying principles and the practical working of certain phases of primitive society.

Mr. C. S. Myers analysed the emotional life of the inhabi. tants of Murray Island, which he studied in the course of the Cambridge expedition to Torres Strait. The excitability of the native is due rather to the varying sanctions of society than to distinctive mental constitution.

Mr. W. Crooke described the organisation of the projected Ethnographic Survey of India and offered criticisms in detail, regretting, in particular, that it had not been found possible to 